\title{
ANALISA TERHADAP PEMAHAMAN AKHLAQ TERHADAP DIRI SENDIRI, SERTA BAGAIMANA IMPLEMENTASINYA DALAM REALITAS KEHIDUPAN (Akhlaq Kepada Diri Sendiri)
}

\author{
Al-Bahra bin Ladjamuddin ${ }^{1}$ \\ Dosen STMIK Raharja Tangerang ${ }^{1}$ \\ Jl. Jendral Sudirman No. 40, Modern Cikokol, Tangerang ${ }^{I}$ \\ Email :albahra@ raharja.info ${ }^{l)}$
}

\begin{abstract}
ABSTRAK
Dewasa ini akhlaqmasyarakat dan bangsa ini semakin hancur dan hilang. Hal ini terbukti dengan adanya perilaku-perilaku maksiat yang dilakukan oleh masyarakat Indonesia terutama kaum muda. Perilaku maksiat yang sekarang semakin merajalela di kehidupan masyarakat, sehingga sudah dianggap biasa dan wajar dalam kehidupan keseharian. Perilaku maksiat tersebut juga diawali dengan semakin banyaknya wanita yang bangga mempertontonkan auratnya seakan dirinya adalah miliknya semata. Hal ini tidak terlepas dari kesalahan manusa terutama umat Islam dalam memahamiagama mereka yang dijadikan pedoman hidup dalam mengarungi kehidupanya didunia ini.Salah satu kunci utama dalam membenahi akhlaqmasyarakat dan bangsa ini adalah dengan menitikberatkan pada lingkungan keluarga. Perlu penyadaran terhadap setiap individu dan keluarga, bahwasanya memahami dan berperilaku sesuai akhlaqIslam sangat penting. Pada proses penanaman nilai akhlaq ini yang pertama kali harus ditanamkan adalah nilai-nilai akhlak terhadap diri sendiri, karena semua hal akan dimulai dari diri kita sendiri, setelah diri kita benar-benar berperilaku sesuai dengan akhlaq Islam, maka secara otomatis dapat menjalar dalam aspekaspek kehidupan yang lain.
\end{abstract}

Kata Kunci : Akhlaq, Aurat, Perilaku Maksiat, Kesadaran

\section{PENDAHULUAN}

\section{Latar Belakang Masalah}

Akhlaq didalam Islam sangatlah berbeda dengan budi pekerti, sopan santun, etika, atau moral. Aktualisasi akhlaq adzimah dan karimah akan dirasakan oleh manusia dalam kehidupan perseorangan, berkeluarga, bertetangga, bermasyarakat dan bernegara. Manusia tanpa akhlaq akan kehilangan derajat kemanusiaannya, bahkan akan lebih rendah derajatnya dari pada binatang. Apabila aktivitas akal manusia tidak dibimbing dengan akhlaq adzimah dan karimah, maka kehancuran dalam masyarakat tidak dapat dibendung lagi. Dengan memahami, menghayati serta mengamalkan akhlaq adzimah dan karimah diharapkan manusia mampu untuk mengendalikan diri, memperhatikan kepentingan orang lain, penuh tenggang rasa, mampu memupuk rasa persatuan dan kesatuan dalam hidup bermasyarakat dan bernegara, serta dapat hidup sebagai warga negara yang baik, yang selalu mengikuti aturan Allah dan Rasul-Nya yang telah di terjemahkan dalam visi, misi, tujuan, sasaran, dan dan strategi pencapaian suatu negara. 
Akhlaq adalah bentuk jamak (plural) dari kata khuluq. Dalam Al-Qur'an kata khuluq disebut diantaranya pada surat Al-Qalam ayat 4, "dan Sesungguhnya kamu benar-benar berbudi pekerti yang agung”. (QS:Al-Qalam:4). Sedangkan dalam hadits banyak disebutkan diantaranya, ketika Siti Aisyah ditanya oleh para sahabat tentang akhlaq Rasulullah SAW, ia menjawab dengan singkat: (كَانَ خُقُةُ الثُرَآن) "Akhlaq Rasulullah sawSAW adalah AlQur'an'.(HR.Muslim)

$$
\text { (انّمابعثت لأتمّم مكارم الأخلاق (رواهالبخاري }
$$

"Sesungguhnya aku diutus hanyalah untuk menyempurnakan akhlaq manusia".

Akhlak merupakan penyempurna keimanan. Rasulullah SAW bersabda, "Orang mukmin yang paling sempurna keimanannya adalah yang paling baik akhlaknnya." (HR. Tirmidzi dan Ahmad). Pemberat timbangan (kebaikan) pada hari kiamat. Rasulullah SAW bersabda:"Tidak ada sesuatu yang dapat memperberat timbangan (kebaikan) seorang mu'min pada hari kiamat selain kebaikan akhlaknya." (HR. Tirmidzi). Pengantar ke surga. Rasulullah SAW bersabda:" Taqwa kepada Allah dan Akhlaq yang baik." (HR. Tirmidzi). Dengan akhlak dapat diperoleh kecintaan dan kedekatan dengan Nabi pilihan, Nabi Muhammad saw. Rasulullah saw bersabda:"Sesungguhnya orang yang paling aku cintai dan paling dekat kedudukannya denganku pada hari kiamat adalah yang paling baik akhlaqnya." (HR. Tirmidzi).

Akhlaq dalam Islam sangatlah komprehensif yang mengatur seluruh sistem kehidupan umat manusia di alam dunia ini. Akhlaq dalam Islam akan mengatur :

a. Secara vertikal, yaitu mengatur bagaimana akhaq manusia terhadap Allah, Malaikat, Nabi dan Rosul, Kitab-Kitab Allah, dan Qadha dan Qhodar

b. Secara horizontal, yaitu mengatur bagaimana akhaq manusia dengan manusia yaitu akhlaq terhadap diri sendiri, orang tua, anak-anak, umat non-muslim

c. Secara horizontal, yaitu mengatur bagaimana akhaq manusia dengan makluq diluar manusia seperti tumbuh-tumbuhan, hewan, alam semesta (gunung, lautan, tata surya udara), juga jin dan syaithon.

Mengingat sedemikian luasnya bahasan aklaq dalam Islam, maka penulis membatasi kajian ini hanya pada bahasan Analisa Terhadap Pemahaman Akhlaq Terhadap Diri Sendiri, Serta Bagaimana Implementasinya Dalam Realitas Kehidupan.

\section{Tujuan Penulisan}

Tujuan yang akan diperoleh dari penulisan kajian ini adalah diharapkan pembaca terutama umat Islam dapat memahami bagaimana berakhlaq terhadap dirinya sendiri baik dalam unsur jasad maupun nafsiyahsesuai dengan aturan yang telah Allah berikan yaitu AlQur'an dan Sunnah.

\section{HASIL ANAISA DAN PEMBAHASAN}

Manusia sebagai makhluk Allah mempunyai kewajiban terhadap dirinya sendiri. Namun bukan berarti kewajiban ini lebih penting daripada kewajiban kepada Allah. Dikarenakan kewajiban yang pertama dan utama bagi manusia adalah mempercayai dengan keyakinan yang sesungguhnya bahwa "Tiada Tuhan melainkan Allah". Keyakinan pokok ini 
merupakan kewajiban terhadap Allah sekaligus merupakan kewajiban manusia bagi dirinya untuk keselamatannya.

Manusia mempunyai kewajiban kepada dirinya sendiri yang harus ditunaikan untuk memenuhi haknya. Kewajiban ini bukan semata-mata untuk mementingkan dirinya sendiri atau menzalimi dirinya sendiri. Manusia mempunyai tiga unsur, yakni jasmani (jasad), rohani, dan nafsiah (jiwa). Dengan memiliki nafsiah (jiwa) ini-lah yang membedakan manusia dengan makhluk Allah yang lainnya. Tiap-tiap unsur memiliki hak di mana antara satu dan yang lainnya mempunyai kewajiban yang harus ditunaikan untuk memenuhi haknya masingmasing.

Akhlaq tidaklah sama dengan etika, sopan santun, tata krama, adat istiadat, dll. Karena Akhlaq landasannya adalah Aqidah (Aqidah Tauhid), dan Syari'ah (hukum). Syari'ah merupakan sarana dan prasarana melaksanakan ibadah secara totalitas kepada Allah. Syari'ah juga akan menjadi mekanisme dan aturan-aturan baku dalam melaksanakan akhlaq adzimah. (QS:42:13) dan (QS:3:19,85). Khuluq yang menunjukan arti akhlaq disebutkan Al-Qur'an dalam dua ayat, yakni Qs. 26:137 dan Qs. 68:4.Qs. 26:137, dan "Dan sesungguhnya kamu benar-benar berbudi pekerti yang agung” Qs. 68:4. Beberapa akhlaq terhadap diri sendiri yang akan diuraikan disini adalah :

\section{AkhlaqTerhadap Jasadiyah (Fisik-Jasmani)}

Akhlaq terhadap jasadiyah yang harus dilakukan oleh seorang muslim dan mu'min adalah :

a. Senantiasa Menjaga Kebersihan. Islam menjadikan kebersihan sebagian dari Iman. Seorang muslim harus bersih/suci badan, pakaian, dan tempat, terutama saat akan melaksanakan sholat dan beribadah kepada Allah, di samping suci dari kotoran, suci dari hadats, juga bersih pakaian dan badannya. Menjaga kebersihan badan/tubuh (mandi, menggosok gigi, mengganti baju yang teratur, dll) juga merupakan salah satu akhlaq Islam.Allah SWT berfirman yang artinya, "Mereka bertanya kepadamu tentang haidh. Katakanlah: "Haidh itu adalah suatu kotoran". Oleh sebab itu hendaklah kamu menjauhkan diri dari wanita di waktu haidh; dan janganlah kamu mendekati mereka, sebelum mereka suci. Apabila mereka telah suci, maka campurilah mereka itu di tempat yang diperintahkan Allah kepadamu. Sesungguhnya Allah menyukai orang-orang yang bertaubat dan menyukai orang-orang yang mensucikan diri”. (QS:Al Baqarah:222)

"Janganlah kamu bersembahyang dalam mesjid itu selama-lamanya. Sesungguh-nya mesjid yang didirikan atas dasar taqwa (mesjid Quba), sejak hari pertama adalah lebih patut kamu sholat di dalamnya. Di dalamnya mesjid itu ada orang-orang yang ingin membersihkan diri. Dan sesungguhnya Allah menyukai orang-orang yang bersih". (QS:At-Taubah:108)

b. Menjaga Makan dan Minumnya. Makan dan minum merupakan kebutuhan vital bagi jasmani (tubuh) manusia, jika tidak makan dan minum dalam keadaan tertentu yang normal, maka manusia akan mati. Allah memerintahkan kepada manusia agar makan dan minum dari yang halal dan tidak berlebihan. Sebaiknya sepertiga dari perut untuk makanan, sepertiga untuk minuman, dan sepertiganya untuk udara. Allah berfirman yang artinya, "Maka makanlah yang halal lagi baik dari rezki yang telah diberikan Allah kepadamu; dan syukurilah ni'mat Allah, jika kamu hanya kepada-Nya saja menyembah". (QS:An-Nahl:114) 
c. Menjaga Kesehatan. Menjaga kesehatan bagi seorang muslim adalah wajib dan merupakan bagian dari ibadah kepada Allah, sekaligus melaksanakan amanah dari-Nya. Olahraga atau latihan jasmani sangat penting dalam menjaga kesehatan jasmani. Olahraga yang teratur juga merupakan salah satu dari akhlaq Islam. Orang mukmin yang kuat, lebih baik dan lebih dicintai Allah SWT daripada mukmin yang lemah.Dari sahabat Abu Hurairah, Bersabda Rasulullah, "Mu'min yang kuat lebih dicintai Allahdari mu'min yang lemah, dan masing-masing memiliki kebaikan. Bersemangatlah terhadap hal-hal yang bermanfaat bagimu dan mohonlah pertolongan kepada Allah dan jangan merasa malas, dan apabila engkau ditimpa sesuatu maka katakanlah "Qodarulloh wa maa syaa'a fa'al, Telah ditakdirkan oleh Allah dan apa yang Dia kehendaki pasti terjadi”. (HR. Muslim)

d. Berbusana yang Islami. Setiap manusia (pria ataupun wanita) mempunyaibagian-bagian anggota tubuh yang indah, sehingga bagian-bagian badannya tersebut ada yang harus ditutupi (aurat) karena tidak pantas untuk dilihat orang lain. Dari segi kebutuhan alaminya, badan manusia perlu ditutup dan dilindungi dari gangguan bahaya alam sekitarnya, seperti dingin, panas, dll. Oleh karena itu Allah memerintahkan manusia menutup auratnya dan Allah menciptakan bahan-bahan di alam ini untuk dibuatkan pakaian sebagai penutup badan, untuk menutup aurat.

Aurat pria adalah dari pusar hingga lututnya. Sementara aurat wanita adalah seluruh bagian tubuhnya, kecuali muka dan telapak tangan. Pada setiap bagian tubuh wanita tersebut banyak terdapat keindahan, sehingga harus ditutupi agar tidak menggangu pandangan lawan jenis/pria. Menutup aurat bagi pria dan wanita merupakan salah satu akhlaq terhadap diri sendiri. Allah berfirman yang artinya, "Hai anak Adam, sesungguhnya Kami telah menurunkan kepadamu pakaian untuk menutup 'auratmu dan pakaian indah untuk perhiasan. Dan pakaian takwa itulah yang paling baik. Yang demikian itu adalah sebahagian dari tanda-tanda kekuasaan Allah, mudah-mudahan mereka selalu ingat". (QS:Al-A'raf:26)

\section{BerakhlaqTerhadap Nafsiyah (Jiwa dan Akal)}

Nafsiah adalah unsur yang banyak diterangkan dalam Al-Qur'an. Nafsiah ini yang menjadi khitob setiap kali Al-Qur'an berbicara tentang manusia. Karena anfusiyah inilah yang merupakan unsur hakiki dari manusia.

Firman Allah yang artinya, "....Kemudian Dia menyempurnakan dan meniupkan kedalam (jasad)nya ruh-Nya, dan dijadikannya bagi kamu pendengaran, penglihatan dan hati, tetapi kamu sedikit sekali bersyukur" (QS:32:9). Dalam ayat ini dijelaskan proses pembentukan jasad manusia. Ketika proses jasmani telah sempurna terbentuk, maka ditiupkanlah Ruh kedalamya, setelah itu dijadikannya sam'a, abshor, dan af'idah.

Sam'a (pendengaran), abshor (penglihatan) dan af'idah (hati) inilah yang disebut (potensi-potensi) Nafsiah. Sam'a, abshor, af'idah tersebut bukan sifat atau potensi yang melekat pada jasmani maupun ruhani, tetapi potensi-potensi yang dimiliki oleh nafsiah (jiwa).

Nafs dengan potensi-potensinya adalah sesuatu yang berbeda dengan unsur jasmani dan ruhani. Walaupun unsur nafsiah ini berada di dalam wadah jasmani, namun ia bukan menjadi bagian dari jasmani. atau sesuatu yang melebur kedalam unsur jasmani. melainkan suatu unsur yang terpisah (mandiri) dan memiliki eksitensi tersendiri yang hakekatnya berbeda dari jasmani maupun ruhani. 
Unsur nafsiah ini tidak dimiliki oleh makhluk lain kecuali manusia. Adanya unsur nafsiah inilah yang menyebakan eksistensi manusia berbeda dengan eksistensi makhluk hidup lain. Sedangkan hewan dan tumbuh-tumbuhan karena tidak memiliki nafsiah, maka keberadaannya tidak memiliki posisi sentral dalam kehidupan di alam semesta ini.

Hewan dan tumbuh-tumbuhan (hayanawat dan nabatat) tidak memiliki potensipotensi nafsiah (sam'a, abshor dan af"idah) seperti yang dimiliki oleh manusia, sehingga hewan dan tetumbuhan tidak memiliki kemampuan untuk menerima, merespon dan mengendalikan kehidupannya. Hewan dan tumbuh-tumbuhan tidak memiliki kecenderungan untuk berbuat fujur dan taqwa, serta tidak memiliki kecendrungan aqal dan hawa yang akan menguasai dirinya. Karena fujur dan taqwa, aqal dan hawa adalah sifat-sifat nafsiah.

Oleh karena itu hewan dan tumbuhan tidak memiliki misi dan tanggung jawab yang harus diemban dalam kehidupannya. Lebih jauhnya mereka tidak memiliki potensi untuk melaksanakan amanah-amanah Allah. Hanya nafsiahlah yang mampu mewujudkan misi amanah tersebut.

Kehidupan hewan dan tumbuh-tumbuhan tidak lebih hanya untuk memenuhi kebutuhan-kebutuhan fisik-jasmaniyahnya semata, hidupnya tidak lain hanya untuk menjalani dan mempertahnkan hidup agar tidak mati, tidak lebih dari itu. Namun demikian itulah bentuk pengabdian mereka terhadap Allah. Sehingga hewan dan tumbuhan tidak dimintai pertanggung jawabannya di sisi Allah kelak.

Sedangkan manusia karena memiliki satu unsur yang berbeda dari binatang dan tetumbuhan tersebut, maka perjalanan hidupnya-pun sangat berbeda. Kehidupan manusia tidak hanya untuk memenuhi kebutuhan fisik-jasmaniyahnya saja agar dapat hidup, tumbuh dan berkembang biak seperti hewan dan tumbuh-tumbuhan, tetapi manusia harus mampu merespon dan mengendalikan kehidupannya sesuai dengan kecenderungan nafsiahnya.

Kehidupan manusia akan berbeda dengan kehidupan hewan dan tumbuh-tumbuhan, jika nafsiah dari manusia tersebut hidup, namun akan menjadi sebaliknya, jika nafsiah manusia (orang) tersebut mati. Mengapa ? Karena ketika nafsiah seseorang "mati" maka tidak ada lagi yang dapat membedakan eksistensinya dengan binatang maupun tetumbuhan, bahkan kondisi manusia yang seperti itu jauh lebih hina dan sesat dari binatang sekalipun.

Unsur nafsiah akan diberikan oleh Allah kepada setiap manusia setelah di tupkannya Ruh. Nafsiah-lah yang membuat perjanjian di hadapan Allah. Dalam QS:7:172 menjelaskan tentang peristiwa syahadah ("pesaksian") yang dilakukan nafsiah ketika di alam rahim. Peristiwa ini terjadi di alam takwin atau alam sebelum manusia dilahirkan ke alam dunia. Nafsiah yang memberi persaksian tentang kerububiyahan Allah.

Saat lahir ke alam dunia jasad dan nafsiah manusia dalam keadaan fitrah/suci, walau ia dilahirkan dari rahim ibu yang anti Islam sekalipun. Orang tua, lingkungan dan sistem pemerintahan yang dapat merubah atau mempertahankan kehidupan/fitrah nafsiah tersebut.

Jasad/fisik akan tumbuh dan berkembang sesuai dengan kodratnya, jika di berikan pasokan makanan yang sesuai dengan kebutuhannya, yaitu : nasi, sayuran, buah-buahan, pendidikan matematika, pendidikan psikologi, pendidikan teologi, dll, maka jasad/fisik manusia akan tumbuh dan berkembang dengan baik, dan akan menjadi jasad yang 
baik/berhasil seperti menjadi guru, menjadi pengusaha, menjadi teknokrat, menjadi psikolog, dll.

Begitu juga sebaliknya dengan nafsiah, sejak lahir nafsiah harus di pertahankan dan di berikan pasokan makanan yang sesuai juga dengan kebutuhannya. Makanan untuk nafsiah adalah dzikrullah, ibadah, mendengar dan mengkaji ayat-ayat Allah, mengkaji nilai-nilai keislaman. Jika sejak lahir nafsiah selalu mendapatkan pasokan yang sesuai, maka nafsiah akan tumbuh berkembang seperti jasad, dan menjadi nafsiah yang sempurna, yaitu menjadi manusia-manusia yang sholeh, tawadhu, selalu bersyukur, dan menjadi manusia yang muttaqien.

Jika pasokan makanan untuk nafsiah kurang (jarang sekali berinteraksi dengan nilainilaiIslam), sementara pasokan makanan untuk jasadiah cukup, maka pertumbuhannya tidak seimbang, dalam istilah lain sering di sebut hati yang sakit. Sehingga bisa saja di temukan manusia dengan jasad berumur 24 tahun, namun nafsiahnya bisa saja masih kecil/sedang sakit, sehingga manusia seperti ini tidak merasa malu jika tidak menutup auratnya di tempattempat umum, manusia seperti ini masih banyak melanggar perintah Allah, masih banyak berbuat dosa, dan maksiat. Seperti ada ungkapan "kok sudah dewasa tidak malu ya keluar rumah tidak memakai jilbab ?, kok sudah dewasa masih saja berbuat maksiat ?. Inilah beberapa contoh manusia yang jasad nya sehat-segar bugar, namun nafsiah-nya masih kecil, sehingga tidak merasa berdosa melanggar perintah Allah.

Jika sejak lahir pasokan makanan untuk nafsiah tidak pernah diberikan, maka lama kelamaan nafsiah akan sakit, bahkan nafsiah seseorang bisa mati, jika tidak mendapat makanan yang sesuai dengan kebutuhannya, dalam istilah Al-Qur'an adalah Qalbun Mayyit. Manusia yang nafsiahnya sudah mati, dikatakan hidup, hanya karena masih ada ruh di dalam jasadnya. Manusia seperti ini akan selalu berbuat dosa, selalu bermaksiat kepada Allah, selalu melanggar perintah Allah, bahkan berani menantang Allah dengan berbuat dosa sebanyak mungkin, selalu berzinah, membunuh, memfitnah, dll.

Lantas mengapa usur nafsiah dikatakan sebagai unsur hakiki manusia ? Dimana semua kehidupan manusia di dunia ini bergantung pada nafsiah tersebut ?. Dan bagaimana kaitan atau hubungan antara unsur nafsiah tersebut dengan unsur-unsur lainnya (jasmani dan ruhani)?.

Dalam Al-Qur'an menjelaskan bahwa Allah telah mengilhamkan kedalam jiwa dua jalan yakni fujur dan taqwa, "Dan demi jiwa serta penyempurnaannya. Makaallah mengilhamkan kepada jiwa itu jalan kefajiran dan ketaqwaan. Sesungguhnya beruntunglah orang yang menyucikan jiwanya. Dan sesungguhnya merugilah orang yang mengotorinya". (QS:91:7-10)

Ayat tersebut menjelaskan bahwa dalam nafsiah ini terdapat dua kecenderungan; pertama yang bersifat positif(taqwa) dan kedua yang bersifat negatif (fujur). Dengan demikian nafsiah manusia bisa terjerumus ke dalam kefajiran atau sebaliknya mencapai ketaqwaan. Nafsiah manusia selalu berada diantara tarik menariknya antara fujur dan taqwa. Itulah sebabnya mengapa tidak setiap manusia berbuat taqwa dan tidak seluruh manusia berbuat fujur. Setiap manusia memiliki kecenderungan untuk berbuat jahat, nista, aniyaya atau sebaliknya berpotensi untuk berbuat baik, jujur, adil dan lain-lain.

Sedangkan fujur atau taqwanya nafsiah tersebut tergantunng pada sejauh mana perebutan antara aqal dan hawa. Jika aqal dapat mendominasi dan menguasai diri sseorang, 
maka ia akan cenderung kepada taqwa, sebalikya jika yang mendominasi nafsiah adalah hawa, maka ia akan cenderung kepada fujur dalam sebuah hadits disbutkan, "Thuba liman kama aqluhu amiron wahawahu asyiron, wal wadu liman kama aqluhu asiron wahawahu amiiron”, yang artinya“Berbahagialah bagi seseorang yang akalnya menjadi pimpinan dan hawanya sebagai tawanan, dan celakalah bagi seseorang yang akalnya menjadi tawanan dan hawanya menjadi pimpinan".

Aqal adalah lawan dari hawa. Kalau sifat hawa adalah cenderung kepada fujur (negatif), sedangkan aqal cenderung kepadataqwa (positif).Nafsiah yang dikuasai oleh aqal adalah nafsiah yang hidup. Tumbuh dan berkembang. Sabaliknya jika hawa yang menguasai nafsiah maka potensi-potensi nafsiah adalah kematian.

Sedangkan nafsiah yang dikuasai oleh hawa adalah nafsiah yang "mati". Nafsiah yang mati ditandai dengan tidak berfungsinya potensi sam'a (pnglihatan), abshor (pendengaran), dan af'idah (hati), artinya ia tidak mampu lagi melihat mendengar dan mengetahui yang mana al-haq dan yang mana al-bathil, mana tujuan dan tugas serta tanggung jawab hidup sebenarnya yang harus ia laksanakan.

Jika hawa yang telah mendominasi nafsiahnya, maka segala tujuan, orientasi, dan aktivitas hidupnya tidak lain hanya untuk kepentingan hawa nafsunya tesebut. Hidup dan kehidupannya tidak lain hanya karena tidak mati saja, perilakunya menjadi seperti binatang, bahkan lebih sesat dan hina dari itu.

QS:7:179 dan QS:6:39,25 menggambarkan tentang manusia yang potensi-potensi nafsiahnya telah mati (tidak berfugsi), penglihatan, pendengaran, dan hatinya telah tertutup. Sehingga ia tidak lagi mampu merespon terhadap keadaan-keadaan yang dihadapinya. Tetapi sebaliknya keadaan atau alam fisiknyalah yang mengendalikan nafsiahnya.

Akhirnya ia terjebak dalam kungkungan alam duniawi yag mengikatnya, dan tidak mampu membebaskan dan melepaskan nafsiahnya dari belenggu tersebut. Ketika nafsiah seseorang telah mati, maka akibatnya ia tidak lagi memiliki perhatian dan keperdulian terhadap nilai-nilai kebaikan, kebenaran, kemuliaan, kesejahteraan dan lain-lain, yang semua itu sesungguhnya adalah kebutuhan hakiki dirinya.

Karena nafsiah adalah hakekat/unsur terpenting dari manusia itu sendiri, maka dapat dipahami mengapa Allah menilai seseorang dari nafsiahnya, bukan dari segi fisik jasmaniyah seperti ditegasan dalam hadits yang artinya, "Sesungguhnya Allah tidak melihat bentuk wajahmu dan tidak pula tubuhmu, akan tetapi Allah melihat ini, hatimu dan perbuatanmu".

Mengapa demikian? Karena dalam hal fisik-jasmani seiap manusia telah ditentukan oleh Allah sejak awal proses penciptaannya, sehingga seseorang tidak bisa menolak atau mengelak terhadap wujud jasmaninya sendiri, apakah ia berjenis kelamin wanita atau lakilaki, berkulit hitam atau bule, hidung mancung atau pesek, berambut pirang atau hitam, keturunan asia atau Afika atau Amerika dan lain sebaginya.

Semua itu adalah mutlak ketentuan Allah semata, dan diluar dari kehendak manusia itu sendiri. Karena masalah jasmani adalah ketetapan Allah semata, maka setiap manusia tidak memiliki kemampuan dan kekuatan sedikitpun untuk merubah atau menggantinya. Oleh karena itu, Allah tidak menilai manusia dari segi jasmani yang memang telah ditetapkan-Nya, 
tetapi Allah akan menilai kepada hati dan amaliyah orang tersebut, karena perkembangan dan pertumbuhan hati serta banyaknya amal seseorang adalah tergantung pada orang tersebut.

Tertutup tidaknya hati (qolbu) dan banyak atau sedikitnya amal, bukan sesuatu yang telah Allah tetapkan pada diri sseorang sejak lahir, akan tetapi semua itu tergantung pada sejauh mana orang tersebut berusaha untuk menghidupkan hatinya (potesi nafsiah), serta memperbanyak amal ibadahnya selama ia hidup di alam dunia ini. Yang dimaksud hati (qolbu) dalam hadits tersebut jelas bukan hati jasmani, tetapi hati nafsiah (jiwa), kaena hanya hati nafsiah-lah yang dapat mendorong seseorang untuk beramal ibadah di sisi Allah.

Berkaitan dengan akhlaq seorang muslim terhadap nafsiah, maka pasokan makanan yang harus diberikan harus sesuai juga dengan kebutuhannya. Makanan untuk nafsiah adalah dzikrullah, ibadah, mendengar dan mengkaji ayat-ayat Allah, mengkaji nilai-nilai keislaman. Jika sejak lahir nafsiah selalu mendapatkan pasokan yang sesuai, maka nafsiah akan tumbuh berkembang seperti jasad, dan menjadi nafsiah yang sempurna, yaitu menjadi manusiamanusia yang sholeh, tawadhu, selalu bersyukur, dan menjadi manusia yang muttaqien.

a. Menuntut Ilmu. Menuntut ilmu merupakan salah satu kewajiban bagi setiap muslim, sekaligus sebagai bentuk akhlak seorang muslim. Muslim yang baik, akan memberikan porsi terhadap akalnya yakni berupa penambahan pengetahuan dalam sepanjang hayatnya. Rasulullah SAW bersabda yang artinya, "Menuntut ilmu merupakan kewajiban bagi setiap muslim.” (HR. Ibnu Majah)

Ilmu yang pertama-tama harus di kuasai adalah ilmu Islam.Setiap muslim berkewajiban mempelajari Al-Qur'an, baik dari segi bacaan, tajwid dan tafsirnya; kemudian ilmu hadits; sirah dan sejarah para sahabat; syari'ah terutama yang terkait dengan permasalahan kehidupan sehari-hari.

b. Mengajarkan Ilmu pada Orang Lain. Termasuk akhlak muslim terhadap akalnya adalah menyampaikan atau mengajarkan apa yang dimilikinya kepada orang yang membutuhkan ilmunya.Firman Allah yang artinya, "Dan Kami tidak mengutus sebelum kamu, kecuali orang-orang lelaki yang Kami beri wahyu kepada mereka; maka bertanyalah kepada orang yang mempunyai pengetahuan, jika kamu tidak mengetahui” (QS:An-Nahl:43)

c. Mengamalkan Ilmu dalam Kehidupan. Diantara tuntutan dan sekaligus akhlak terhadap akalnya adalah seorang muslim harus merealisasikan ilmunya dalam "alam nyata." Karena akan berdosa seorang yang memiliki ilmu namun tidak mengamalkannya.Firman Allah yang artinya, "Wahai orang-orang yang beriman, kenapakah kamu mengatakan sesuatu yang tidak kamu kerjakan? Amat besar kebencian di sisi Allah bahwa kamu mengatakan apa-apa yang tidak kamu kerjakan." (QS:As-Shaff)

d. Bertaubat dan Menjauhkan Diri dari Perbuatan Dosa. Taubat adalah meninggalkan seluruh dosa dan kemaksiatan, menyesali perbuatan dosa yang telah lalu, dan berkeinginan teguh untuk tidak mengulangi lagi perbuatan dosa tersebut pada waktu yang akan datang.Allah berfirman yang artinya, "Hai orang-orang yang beriman, bertaubatlah kepada Allah dengan taubatan nasuhaa (taubat yang semurni-murninya). Mudahmudahan Robbmu akan menutupi kesalahan-kesalahanmu dan memasukkanmu ke dalam jannah yang mengalir di bawahnya sungai-sungai, pada hari ketika Allah tidak menghinakan Nabi dan orang-orang mu'min yang bersama dia; sedang cahaya mereka memancar di hadapan dan di sebelah kanan mereka, sambil mereka mengatakan: "Ya Robb kami, sempurnakanlah bagi kami, cahaya kami dan ampunilah kami; Sesungguhnya 
Engkau Maha Kuasa atas segala sesuatu." (QS:At-Tahrim:8). Adapun yang termasuk dalam perbuatan dosa diantaranya adalah : Berbuat syirik, Kufur, Berlaku Nifak, Membunuh manusia, Bersumpah palsu, Berzina dan menuduh orang lain berzina, melakukan perbuatan yang mendekati zina (Seperti berpacaran, tidak menutup aurat, dll),

e. Bermuraqabah. Muraqabah adalah rasa kesadaran seorang muslim, bahwa dia selalu diawasi oleh Allah. Dengan demikian dia tidak akan berani melakukan perbuatan yang melanggar perintah Allah. Firman Allah yang إنَّ اللَّ عَلْيكُمْ رَفَقِيبًا artinya, "Sesungguhnya Allah itu maha mengawasimu.” (QS:An-Nisa:1)

f. Bermuhasabah. Muhasabah adalah menyempatkan diri pada suatu waktu untuk menghitung-hitung amal hariannya. Apabila terdapat kekurangan pada yang diwajibkan kepadanya, maka menghukum diri sendiri dan berusaha memperbaikinya. Kalau termasuk yang harus diqadha maka mengqadhanya. Dan bila ternyata terdapat sesuatu yang terlarang maka memohon ampun, menyesali dan berusaha tidak mengulangi kembali. Muhasabah merupakan salah satu cara untuk memperbaiki diri, membina, menyucikan, dan membersihkannya.Firman Allah yang artinya, "Hai orang-orang yang beriman, bertakwalah kepada Allah dan hendaklah setiap diri memperhatikan apa yang telah diperbuatnya untuk hari esok (akhirat); dan bertakwalah kepada Allah, sesungguhnya Allah Maha Mengetahui apa yang kamu kerjakan.” (QS:Al-Hasyr:18)

g. Mujahadah. Mujahadah adalah berjuang, bersungguh-sungguh, berperang melawan hawa nafsu. Hawa nafsu senantiasa mencintai ajakan untuk terlena, menganggur, tenggelam dalam nafsu yang menghembuskan syahwat, kendatipun padanya terdapat kesengsaraan dan penderitaan. Firman Allah yang artinya, "Dan aku tidak membebaskan diriku (dari kesalahan), karena sesungguhnya nafsu itu selalu menyuruh kepada kejahatan, kecuali nafsu yang diberi rahmat oleh Tuhanku. Sesungguhnya Tuhanku Maha Pengampun lagi Maha Penyanyang. ” (QS:Yusuf:53)

\section{KESIMPULAN}

Manusia mempunyai kewajiban kepada dirinya sendiri yang harus ditunaikan untuk memenuhi haknya. Kewajiban ini bukan semata-mata untuk mementingkan dirinya sendiri atau menzalimi dirinya sendiri. Manusia mempunyai tiga unsur, yakni jasmani (jasad), rohani, dan nafsiah (jiwa). Dengan memiliki nafsiah (jiwa) ini-lah yang membedakan manusia dengan makhluk Allah yang lainnya. Tiap-tiap unsur memiliki hak di mana antara satu dan yang lainnya mempunyai kewajiban yang harus ditunaikan untuk memenuhi haknya masingmasing.

Macam-macam akhlak seorang muslim pada diri sendiri yaitu berakhlaq terhadap jasmani, meliputi menjaga kebersihan, menjaga makan dan minum, menjaga kesehatan, serta melindungi anggota tubuhnya dengan cara menutup auratnya baik pria maupun wanita sesuai dengan batasan aurat yang diatur oleh Allah Azza wa Jalla. Selain itu berakhlaqq terhadap jiwa, meliputi bertaubat dan menjauhkan diri dari dosa besar, bermuraqqabah, bermuhasabbah, dan mujahadah. 


\section{DAFTAR PUSTAKA}

[1] Al-bahra bin Ladjamuddin, Mukti Budiarto, Tuti Nurhaeni, "Analisa Terhadap Pergeseran Peran Strategis Wanita di Era Informasi Serta Solusinya Menurut Islam", Journal CICES Vol.1 No.1 Agustus 2015, Perguruan Tinggi Raharja Press.

[2] Abu Bakar Jabir El Jazairi.1993.Pola Hidup Muslim (MinhajulMuslim):Etika.Bandung : PT Remaja Rosdakarya.

[3] Mohammad Urfan, Desy Apriani, Dedeh Supriyanti, "Tinjauan Realitas Terhdap Status Peran dan Fungsi Manusia", Journal CICES Vol.1 No.1 Agustus 2015, Perguruan Tinggi Raharja Press.

[4] Rahmat Djatnika.1996. Sistem Etika Islami : Akhlak Mulia.Jakarta: Pustaka Panjimas.

[5] Miftah Faridl.1997.Etika Islam: Nasehat Islam untuk Anda.Bandung: Pustaka.

[6] Rikza Maulan, akhlak terhadap diri sendiri. Dalam alamat :http://www.slideshare.net/rilamaulida04/akhlak-2 kamis, 12.04.13.58

[7] Agung Kusuma Sikum bang, akhlak terhadap diri sendiri. Dalam alamat : http://azemmutawakkil.multiply.com/journal/item/6?\&show_interstitial=1\&u=\%2Fjour nal\%2Fitem. Kamis,12 April 2012 jam 12.00 WIB 